Provided for non-commercial research and education use. Not for reproduction, distribution or commercial use.

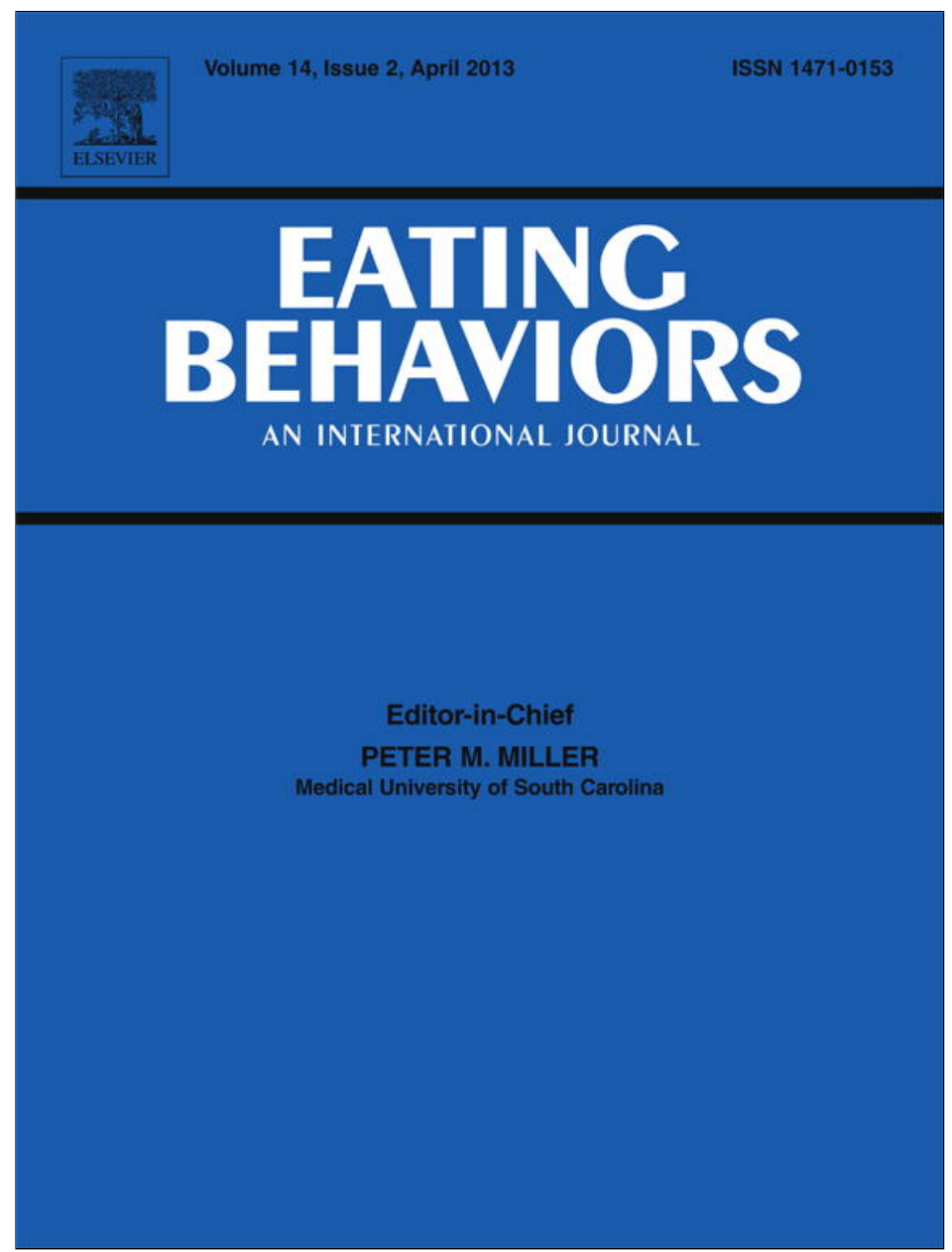

This article appeared in a journal published by Elsevier. The attached copy is furnished to the author for internal non-commercial research and education use, including for instruction at the authors institution and sharing with colleagues.

Other uses, including reproduction and distribution, or selling or licensing copies, or posting to personal, institutional or third party websites are prohibited.

In most cases authors are permitted to post their version of the article (e.g. in Word or Tex form) to their personal website or institutional repository. Authors requiring further information regarding Elsevier's archiving and manuscript policies are encouraged to visit:

http://www.elsevier.com/authorsrights 


\title{
The relationships among psychiatric medications, eating behaviors, and weight
}

\author{
Karen M. Davison * \\ Department of Community Health Sciences, Faculty of Medicine, University of Calgary, Canada
}

\section{A R T I C L E I N F O}

\section{Article history:}

Received 8 July 2012

Received in revised form 21 November 2012

Accepted 15 January 2013

Available online 9 February 2013

\section{Keywords:}

Psychiatric medications

Eating behaviors

Eating attitudes

Cognitive dietary restraint

Disinhibition

Weight

\begin{abstract}
A B S T R A C T
To help address gaps in information about the links that exist between psychiatric medications and weight changes, an investigation of relationships among select psychotropic agents (i.e., mood stabilizers, antidepressants, and second-generation antipsychotics $\{$ SGAs\}), eating behaviors, and weight was conducted. Data from a cross-sectional study of food habits in 97 individuals with mood disorders was used. Variables measured included use of psychotropic agents, measures of cognitive dietary restraint and disinhibition from the Three Factor Eating Behavior Questionnaire (TFEQ), psychiatric functioning, reported weight gain and measured BMI. The TFEQ measures were compared to population norms. Bivariate and multivariate analyses examined the relationships among the psychotropic agents, eating behaviors, and weight. Indicators of cognitive dietary restraint and disinhibition were higher than population norms ( $p$ 's $<0.05$ to $0.0001)$. Depression was associated with restraint $(\mathrm{rho}=0.21, \mathrm{p}<0.05)$. BMI was associated with disinhibition ( $\mathrm{p}<0.05$ ); antidepressant use appeared to moderate weight for those taking SGAs and mood stabilizers $(\mathrm{p}<0.05)$. Exploration of the interacting mechanisms of psychotropic agents and attention to eating attitudes and behaviors of individuals taking psychiatric medications might lessen pharmaceutical-induced weight gain. Prospective research on large samples that can make comparisons to those who are untreated is needed.
\end{abstract}

(C) 2013 Elsevier Ltd. All rights reserved.

\section{Introduction}

Weight gain is often associated with the use of mood stabilizers, antipsychotics, and antidepressants (Allison et al., 1999; Parsons et al., 2009; Vanina et al., 2002) which can lead to issues such as metabolic syndrome, cardiovascular disease, medication non-compliance, and relapse risk (Archie et al., 2007). The weight gain experienced while taking psychiatric medications may be due to hyperphagia from lack of satiation (Costa et al., 2001), altered energy homeostasis, and/or endocrine disturbances (Esen-Danaci, Sarandol, Taneli, Yurtsever, \& Ozlen, 2008).

Dietary restraint, the intention to restrict food intake to control body weight, and disinhibition or the tendency to overeat in the presence of disinhibiting stimuli (e.g., palatable foods, emotional stress) (Stunkard \& Messick, 1988), have been implicated as determinants of weight gain. Dietary disinhibition is positively associated with weight (Hainer et al., 2006; Hays et al., 2002; Lindroos et al., 1997), but the association between dietary restraint and weight remains unclear (Hainer et al., 2006; Hays et al., 2002; Lauzon-Guillain et al.,

\footnotetext{
* Chronic Condition Self Management, University of British Columbia, School of Population and Public Health, Canada.

E-mail address: kdavison@vivahealthed.com.
}

2006; Lowe et al., 2006) possibly due to interaction effects of restraint and disinhibition (Foster et al., 1998; Hays et al., 2002; Lawson et al., 1995; Williamson et al., 1995).

There has been little investigation of relationships that may exist among the use of psychiatric medications, dietary restraint, disinhibition, and weight. One study reported higher dietary restraint scores in 29 people with schizophrenia who were treated with second generation antipsychotics (SGAs) compared with controls, and found that dietary restraint, as measured by the Three-Factor Eating Questionnaire (TFEQ), correlated positively with disinhibition and BMI (Knolle-Veentjer, Huth, Ferstl, Aldenhoff, \& Hinze-Selch, 2008). Another study examined the TFEQ and the Dutch Eating Behavior Questionnaire (DEBQ) in 93 individuals treated with SGAs, 27 treated with conventional neuroleptics and 33 untreated patients (Sentissi et al., 2009) and found that mean BMI varied significantly among the three groups: DEBQ external eating factor was significantly higher in people treated with SGAs compared to conventional neuroleptics (Sentissi et al., 2009). The TFEQ disinhibition $(p=0.003)$ and hunger scores $(p=0.017)$ increased according to BMI.

Investigation of motivators of eating, weight status and the use of different psychiatric medications could help further the understanding of mechanisms of weight gain that often occurs with these drugs. In a study that characterized food intakes of adults with mood disorders, significantly higher intakes of fatty, 
sugary, and salty foods were found when compared to population norms (Davison \& Kaplan, 2012a, 2012b). Part of this research included collecting data on types of psychiatric medications, dietary restraint, disinhibition, and weight which enabled analysis of the relationships among these variables.

\section{Materials and methods}

\subsection{Sample}

The sample was drawn from a survey on food habits and has been detailed elsewhere (Davison \& Kaplan, 2012a, 2012b). The study's protocol was approved by the University of Calgary's Conjoint Health Research Ethics Board. A clinical interviewer administered the Structured Clinical Interview for DSM-IV Axis I Disorders (SCID) (First, Spitzer, Gibbon, \& Williams, 2001), Global Assessment of Functioning (GAF) scale (Jones, Thornicroft, Coffey, \& Dunn, 1995), Hamilton Depression (Ham-D) scale (Hamilton, 1960), and Young Mania Rating Scale (YMRS) (Young, Biggs, Zieler, \& Meyer, 1978).

\subsection{Eating behavior and weight measurements}

A trained registered dietitian asked questions from the TFEQ (Stunkard \& Messick, 1985). To allow for direct comparisons to the British Columbia Nutrition Survey (BCNS) or regional "population norms" (British Columbia Ministry of Health Services, 2004), five items from the restraint subscale and four items from the disinhibition subscale with the highest item-total correlations to each of the subscale scores were selected for inclusion. Other data collected included age of onset of psychiatric condition, types of medications taken, reported weight changes after starting psychiatric medication, as well as sociodemographic, weight, and height information based on standard protocols (British Columbia Ministry of Health Services, 2004).

\subsection{Data analysis}

Descriptive analyses included using binomial tests of two proportions, as well as parametric and non-parametric statistics where applicable. Three multiple regression models were used to examine the relationships among selected sociodemographic and clinical variables, restraint, disinhibition, and BMI. The data were analyzed using the statistical software program Stata 7.0 (Stata Corporation, 2002).

\section{Results}

\subsection{Sample}

The response rate was $75 \%$ and there were no significant differences between the respondents $(n=97)$ and those who declined participation and completed a non-response survey $(n=11)$ based on a variety of health behaviors such as smoking and multivitamin use. The sample would be described as being mainly females $(n=69$; $71.1 \%$ ) with bipolar disorder (59.8\%), taking psychiatric medication (87.6\%), and having BMIs exceeding $25(n=65 ; 67 \%)$. Their educational attainment levels tended to be less than a bachelor's degree $(\mathrm{n}=76 ; 78.4 \%)$ and they had government-defined low income levels $(\mathrm{n}=47 ; 48.5 \%)$. Psychological data suggested that the sample was generally high functioning; GAF $(62.7 \pm 14.7)$, YMRS (Median $=3$; $\mathrm{IQR}=1,5$ ) and Ham-D scores (Median $=9.6, \mathrm{IQR}=1,31$ ). For those taking mood stabilizers, there was a higher proportion of the sample (35\%) who carried excess weight (BMI $>25)$ when compared to the use of SGAs $(18 \%)$ and antidepressants $(31 \%)(p<0.05)$.
3.2. Restraint and disinhibition: prevalence estimates and sociodemographic differences

The proportion answering yes to individual cognitive dietary restraint and disinhibition questions was higher than population norms (p's $<0.05$ to 0.0001 ), however, only the overall mean disinhibition scores were significantly higher than the BCNS (Table 1). Generally, women were more likely than men to agree with statements reflecting cognitive dietary restraint or disinhibition (range of $\mathrm{p}<0.05$ to $<0.0001)$. However, more males tended to restrict their food intake in a conscious effort to control weight $(\mathrm{p}<0.05)$ or were more likely to go on eating binges $(\mathrm{p}<0.0001)$. Disinhibition scores negatively correlated with age $(\mathrm{rho}=-0.28, \mathrm{p}<0.05)$ and there was a positive correlation between restraint scores and income $(\mathrm{p}<0.05)$. Those who answered affirmatively to the statement "I do not eat some foods because they make me fat" tended to have higher education $(\mathrm{p}<0.05)$.

\subsection{Relationships among restraint, disinhibition, and BMI}

Ham-D and restraint scores were positively correlated $(\mathrm{rho}=0.21$, $\mathrm{p}<0.05)$. Higher BMI was associated with disinhibition $(\mathrm{p}<0.05)$. There tended to be a higher proportion who reported weight changes since starting their psychiatric medications and agreed with dietary restraint and disinhibition statements ( $p$ 's $<0.05$ to 0.0001 ). The use of mood stabilizers was associated with excess weight $(\mathrm{p}<0.05)$ (Table 1$)$. Disinhibition and BMI were significantly associated with interactive effects among select medications (Fig. 1). Antidepressants appeared to moderate the effects of SGAs and mood stabilizers on BMI (p's $<0.05$ ). Interaction was also found between SGAs and mood stabilizers in relationship to disinhibition scores $(\mathrm{p}<0.05)$.

\section{Discussion}

In this study, dietary restraint and disinhibition were significantly more prevalent than population norms and were associated with weight gain. While disinhibition was positively correlated with BMI, restraint was associated with depression. Antidepressant use was associated with components of disinhibition and moderated relationships between BMI, SGAs and mood stabilizers. Disinhibition was associated with the interaction of SGAs and mood stabilizers.

The results support different theories about cognitive dietary restraint, disinhibition and weight. The finding that a lower proportion of individuals reported weight gain when some dietary restraint was present support the hypotheses that cognitive dietary restraint contributes to weight suppression (Barr \& Rideout, 2009) and may help with weight management. Conversely, high dietary restraint may have serious implications as it can create psychological stress that activates the hypothalamic-pituitary-adrenal axis, increases release of cortisol (Miller \& O'Callaghan, 2002), and affects mood stability (McEwen \& Stellar, 1993). Prospective investigations could determine if depression can be attributed to altered nutrition and metabolic functions or if the psychological effects of restraint, separate from biochemical changes due to diet, affect psychiatric symptoms; it is likely the relationships between food restriction and negative mood state are interactive. Finally, the correlation between BMI and disinhibition scores may lend support to theories regarding the relationships among the neurotransmitters serotonin and histamine with control of appetite (Blouin et al., 2008).

Some of the findings of this study were unexpected and should be interpreted with caution. It was surprising that only mood stabilizers were associated with excess weight and that there were significant interactions among antidepressants, SGAs and mood stabilizers with BMI. While the exact mechanisms of action for antidepressants, 
Table 1

Agreement with statements about eating restraint and dietary disinhibition with comparison to the BCNS and by type of mood disorder, psychiatric medication and BMI status.

\begin{tabular}{|c|c|c|c|c|c|c|c|}
\hline \multirow[t]{2}{*}{ Statements reflecting cognitive dietary restraint ${ }^{\mathrm{a}}$} & \multirow{2}{*}{$\begin{array}{l}\text { Study, }\{\text { BCNS }\}^{b} \\
n(\%)\end{array}$} & \multicolumn{3}{|c|}{ Type of medication $(\%)^{c}$} & \multicolumn{2}{|l|}{ BMI } & \multirow{2}{*}{$\begin{array}{l}\text { Weight gain }(\%) \\
(\mathrm{n}=40)\end{array}$} \\
\hline & & $\begin{array}{l}\mathrm{SGA}^{\mathrm{d}} \\
(\mathrm{n}=26)\end{array}$ & $\begin{array}{l}\mathrm{AD}^{\mathrm{e}} \\
(\mathrm{n}=44)\end{array}$ & $\begin{array}{l}M S^{f} \\
(n=46)\end{array}$ & Mean \pm SD & $\begin{array}{l}\geq 25(\%) \\
(n=61)\end{array}$ & \\
\hline I do not eat some foods because they make me fat & $53^{*}\{40\}$ & 84.6 & 77.3 & 67.4 & $28.3 \pm 5.5$ & 70.5 & $67.5^{* * *}$ \\
\hline I deliberately take small helpings as a means of controlling my weight & $51^{* * *}\{29\}$ & 69.2 & 68.2 & 69.6 & $28.8 \pm 6.0$ & 75.4 & $77.5^{* * * *}$ \\
\hline \multicolumn{8}{|l|}{$\begin{array}{l}\text { How often are you restricting your food intake in a conscious effort to } \\
\text { control your weight? }\end{array}$} \\
\hline Rarely & $28^{* * *}\{51\}$ & 7.7 & 20.5 & 21.7 & $29.5 \pm 7.9$ & $21.3^{*}$ & 17.5 \\
\hline Sometimes & $31\{29\}$ & 38.5 & 36.4 & 23.9 & $28.6 \pm 6.9$ & 32.8 & 35.0 \\
\hline Usually & $28^{* *}\{15\}$ & 34.6 & 31.8 & 32.6 & $27.7 \pm 3.8$ & 26.2 & 30.0 \\
\hline Always & $13^{*}\{6\}$ & 19.2 & 6.8 & 13.0 & $31.6 \pm 5.3$ & 16.4 & 12.5 \\
\hline \multicolumn{8}{|l|}{ How likely are you to consciously eat less than you want? } \\
\hline Unlikely & $29^{* * *}\{54\}$ & 34.6 & 29.5 & 26.1 & $29.4 \pm 6.5$ & 32.8 & 35.0 \\
\hline Slightly likely & $18\{25\}$ & 19.2 & 15.9 & 19.6 & $29.9 \pm 6.5$ & 20.0 & 25.0 \\
\hline Moderately & $31^{* * * *}\{16\}$ & 23.1 & 36.4 & 26.1 & $28.2 \pm 7.2$ & 29.5 & 22.5 \\
\hline Very likely & $19^{* * *}\{5\}$ & 15.4 & 15.9 & 23.9 & $26.0 \pm 3.6$ & 16.4 & 15.0 \\
\hline \multicolumn{8}{|l|}{ How would you rate your restraint? } \\
\hline Eat whatever you want, whenever you want & $1.0^{* * *}\{22.2\}$ & 1.0 & 0.0 & 0.0 & - & - & - \\
\hline Usually eat whatever you want, whenever you want & $18.6\{24.2\}$ & 5.0 & 8.0 & 8.0 & $32.2 \pm 6.9^{*}$ & 24.6 & $35.0^{*} \mathrm{~g}$ \\
\hline Often eat whatever you want, whenever you want & $17.5\{21.4\}$ & 2.0 & 10.0 & 5.0 & $27.6 \pm 5.1$ & 19.7 & $7.5^{* h}$ \\
\hline Often limit food intake, but often 'give in' & $33.0^{*}\{20.7\}$ & 11.0 & 15.0 & $22.0^{*}$ & $28.1 \pm 4.9$ & 36.1 & 25.0 \\
\hline Usually limit food intake, rarely 'give in' & $18.6^{*}\{10.6\}$ & 6.0 & 9.0 & 6.0 & $28.2 \pm 8.2$ & 16.4 & 25.0 \\
\hline Constantly limit food intake, never 'give in' & $7.2^{* * * *}\{0.9\}$ & 1.0 & 1.0 & 4.0 & $24.3 \pm 3.1$ & 4.9 & 7.5 \\
\hline Restraint scores ${ }^{\mathrm{i}}$ & $1.4 \pm 0.7\{1.3 \pm 1.3\}$ & $1.5 \pm 0.6$ & $1.5 \pm 0.7$ & $1.4 \pm 0.7$ & 0.04 & $1.4 \pm 0.6$ & $1.5 \pm 0.7$ \\
\hline \multirow[t]{2}{*}{ Statements reflecting disinhibition ${ }^{\mathrm{a}}$} & \multirow{2}{*}{$\begin{array}{l}\text { Study, }\{\text { BCNS }\}^{\mathrm{b}} \\
\mathrm{n}(\%)\end{array}$} & \multicolumn{3}{|c|}{ Type of medication $(\%)^{c}$} & \multicolumn{2}{|l|}{ BMI } & \multirow{2}{*}{$\begin{array}{l}\text { Weight gain }(\%) \\
(\mathrm{n}=40)\end{array}$} \\
\hline & & $\begin{array}{l}\mathrm{SGA}^{\mathrm{d}} \\
(\mathrm{n}=26)\end{array}$ & $\begin{array}{l}\mathrm{AD}^{\mathrm{e}} \\
(\mathrm{n}=44)\end{array}$ & $\begin{array}{l}\mathrm{MS}^{\mathrm{f}} \\
(\mathrm{n}=46)\end{array}$ & Mean \pm SD & $\begin{array}{l}\geq 25(\%) \\
(n=61)\end{array}$ & \\
\hline When I feel ‘down' or sad, I often overeat & $46^{* * *}\{20\}$ & 73.1 & 72.7 & 73.9 & $29.1 \pm 5.5$ & $73.8^{*}$ & $77.5^{* * * *}$ \\
\hline Sometimes when I start eating, I just can't seem to stop & $51^{* * *}\{22\}$ & 61.5 & 61.4 & 67.4 & $29.9 \pm 6.6^{*}$ & $67.2^{*}$ & $62.5^{*}$ \\
\hline When I feel lonely, I console myself by eating & $51^{* * *}\{13\}$ & 69.2 & $72.7^{*}$ & 63.0 & $29.5 \pm 6.5$ & 65.6 & $62.5^{*}$ \\
\hline \multicolumn{8}{|l|}{ Do you go on eating binges ${ }^{j}$ even though you are not hungry? } \\
\hline Never & $35^{* * *}\{76\}$ & 26.9 & 50.0 & 26.1 & $28.0 \pm 7.8$ & 31.1 & 13 \\
\hline Rarely & $14\{14\}$ & 7.7 & 26.9 & 13.0 & $27.1 \pm 5.1$ & 11.5 & 5 \\
\hline Sometimes & $36^{* * *}\{8\}$ & 53.8 & 61.5 & 50.0 & $29.4 \pm 4.7$ & 39.3 & 12 \\
\hline \multirow[t]{2}{*}{ At least weekly } & $15^{* * *}\{1\}$ & 11.5 & 23.1 & 4.3 & \multirow{2}{*}{$\begin{array}{l}29.6 \pm 7.9 \\
\text { rho }\end{array}$} & 11.5 & \multirow{2}{*}{$D^{6}$} \\
\hline & Mean \pm SD & & & & & Mean \pm SD & \\
\hline Disinhibition scores ${ }^{\mathrm{k}}$ & $\begin{array}{l}1.9 \pm 1.2^{* * *} \\
\{0.5 \pm 1.0\}\end{array}$ & $2.0 \pm 1.3$ & $2.1 \pm 1.1$ & $2.0 \pm 1.1$ & $0.26^{*}$ & $2.0 \pm 1.1$ & $2.0 \pm 1.1$ \\
\hline
\end{tabular}

Significant differences between study sample and BCNS at: ${ }^{*} \mathrm{p}<0.05,{ }^{* *} \mathrm{p}<0.001$ or ${ }^{* * *} \mathrm{p}<0.0001$.

a Questions from Stunkard and Messick (1985).

b Sample size for study $=97$; sample size for $\mathrm{BCNS}=1823$.

c Statistical comparisons of medication groups based on logistic regression analysis.

d Second-generation antipsychotics included dibenzodiazepine, benzisoxazole, thienobenzodiazepine, indolone, and quetiapine (clozapine, risperidone, olanzapine, molindone, seroquel).

e Anti-depressant medications included the tricyclics, atypicals, selective serotonin reuptake inhibitors, serotonin and norepinephrine reuptake inhibitors, monoamine oxidase

inhibitors, noradrenergics, and specific serotonergics.

${ }_{\mathrm{f}}$ Mood stabilizers included carbamazepine, lithium carbonate, divalproex sodium and valproic acid.

$\mathrm{g}$ Proportion reporting weight gain significantly higher for this response.

h Proportion reporting weight gain significantly lower for this response.

${ }^{i}$ Restraint scores reflect the perception that food intake is consciously limited in an attempt to control body weight. Scores are based on five items taken from the restraint subscale of the Three-Factor Eating Questionnaire (Stunkard \& Messick, 1985).

j Binge eating means eating a very large amount of food in a very short period of time, and feeling that you can't control how much you're eating.

$\mathrm{k}$ Disinhibition scores reflect the perception that control over food intake can be lost in response to certain situations, leading to overeating. Scores are based on four items taken from the disinhibition subscale of the Three-Factor Eating Questionnaire (Stunkard \& Messick, 1985).

SGAs and mood stabilizers are relatively unknown, the results suggest that certain combinations moderate eating and weight. However, this small, hypothesis-generating, cross-sectional study that did not include measures of hunger and dieting behavior, which could help account for effects of eating behavior and weight (Savage, Hoffman, \& Birch, 2009), presents findings that are speculative.

The main results suggest that associations exist among restraint, disinhibition, weight, and psychiatric medication use and that antidepressants combined with SGAs or mood stabilizers may moderate
BMI. Exploration of the interacting mechanisms of antidepressants, SGAs, and mood stabilizers and attention to eating attitudes and behaviors of individuals taking psychiatric medications might lessen pharmaceutical-induced weight gain. However, prospective studies using larger samples and comparisons to those who are untreated are needed.

\section{Role of funding source}

The Danone Research Institute provided financial support for the conduct of this research project. The funder did not have any role in study design, collection, analysis, 

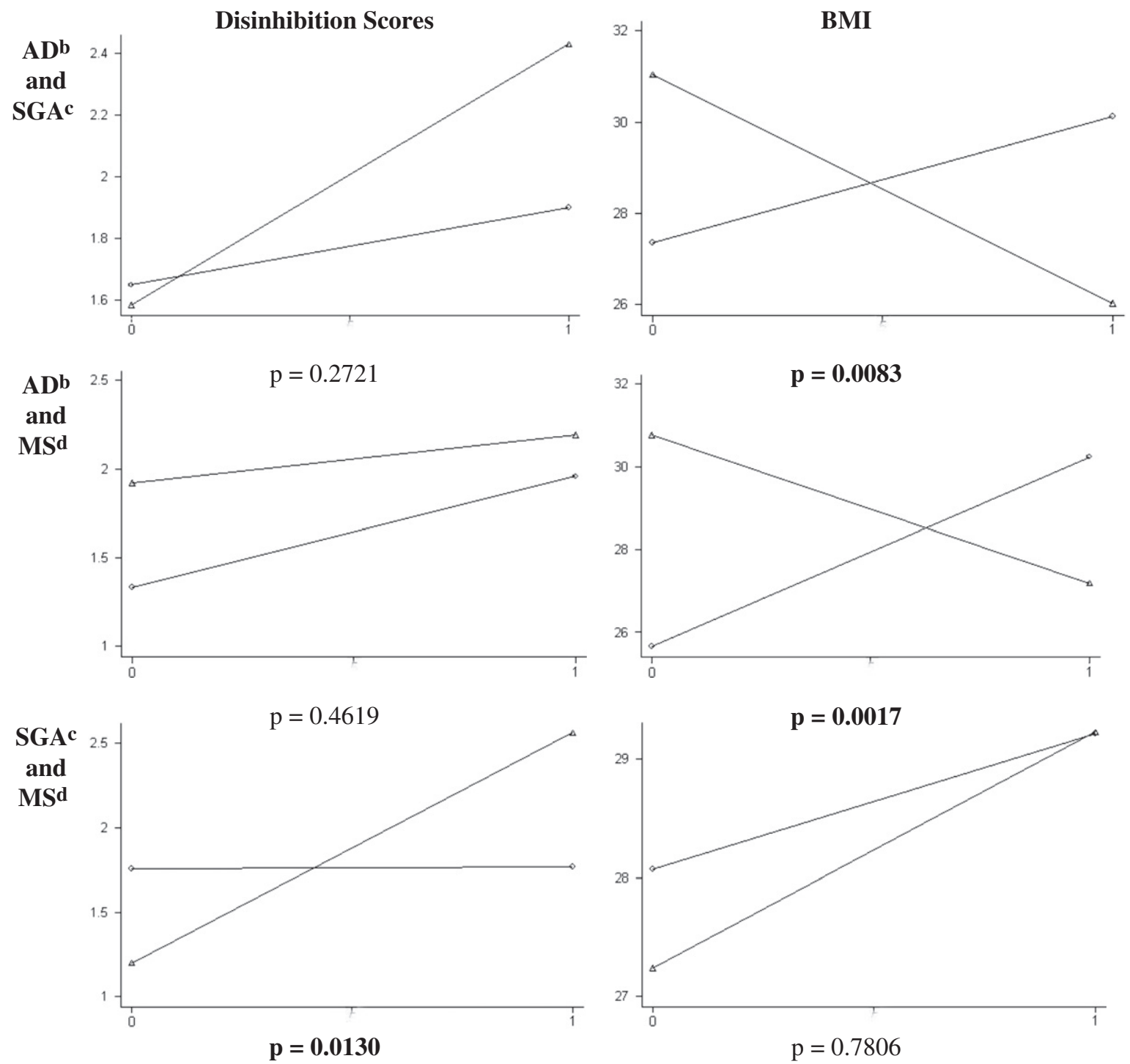

${ }^{\mathrm{a} C}$ Controlling for age, sex, and income

${ }^{\mathrm{b}}$ Antidepressants

${ }^{\mathrm{c}}$ Second-generation antipsychotics

${ }^{\mathrm{d}}$ Mood stabilizers

Bolded p's are significant

Fig. 1. Interaction plots of antidepressants, SGAs and mood stabilizers for disinhibition scores and BMI ${ }^{\mathrm{a}}{ }^{\mathrm{a}}$ Controlling for age, sex, and income. ${ }^{\mathrm{b}} \mathrm{Antidepressants.}{ }^{\mathrm{C}}$ Second-generation antipsychotics. ${ }^{\mathrm{d}}$ Mood stabilizers. Bolded p's are significant.

or interpretation of data, writing the manuscript, or the decision to submit the manuscript for publication.

\section{Contributors}

This work is based on the author's doctoral work at the Department of Community Health Sciences, Faculty of Medicine, University of Calgary, Calgary, Alberta.

\section{Conflict of interest}

The author has no conflicts of interest to declare.

\section{Acknowledgements}

Thank you to Dr. Bonnie J. Kaplan for her insights on the development of the manuscript. Gratitude is also extended to the funding source for this study, the Danone Research Institute and the Mood Disorders Association of British Columbia for providing support staff, office space and assistance with the recruitment.

\section{References}

Allison, D. B., Mentore, J. L., Heo, M., Chandler, L. P., Cappelleri, J. C., Infante, M. C., et al. (1999). Antipsychotic-induced weight gain: A comprehensive research synthesis. The American Journal of Psychiatry, 156, 1686-1696.

Archie, S. M., Goldberg J. O. Akhtar-Danesh, N., Landeen, J., McColl, L., \& McNiven, J. (2007). Psychotic disorders, eating habits, and physical activity: Who is ready for lifestyle changes? Psychiatric Services, 58, 233-239.

Barr, S. I., \& Rideout, C. A. (2009). "Restrained eating" vs "trying to lose weight": How are they associated with body weight and tendency to overeat among postmenopausal women? Journal of the American Dietetic Association, 109, 890-893.

Blouin, M., Tremblay, A., Jalbert, M. E., Venables, H., Bouchard, R. H., Roy, M. A., et al. (2008). Adiposity and eating behaviours in patients under second generation antipsychotics. Obesity (Silver Spring), 16, 1780-1787.

British Columbia Ministry of Health Services (2004). British Columbia nutrition survey: Report on energy and nutrient intakes. Victoria, BC: British Columbia Ministry of Health Services.

Costa e Silva, J. A., Alvarez, N., Mazzotti, G., Gattaz, W. F., Ospina, J., Larach, V., et al 2001). Olanzapine as alternative therapy for patients with haloperidol-induced 
extrapyramidal symptoms: Results of a multicenter, collaborative trial in Latin America. Journal of Clinical Psychopharmacoly, 21, 375-381.

Davison, K. M., \& Kaplan, B. J. (2012a). Food intake and blood cholesterol levels of community-based adults with mood disorders. BMC Psychiatry, 12, 10.

Davison, K. M., \& Kaplan, B. J. (2012b). Nutrient intakes are correlated with overall psychiatric functioning in adults with mood disorders. Canadian Journal of Psychiatry, 57(2), 85-92.

Esen-Danaci, A., Sarandol, A., Taneli, F., Yurtsever, F., \& Ozlen, N. (2008). Effects of second generation antipsychotics on leptin and ghrelin. Progress in Neuro-Psychopharmacology E Biological Psychiatry, 32(6), 1434-1438.

First, M. B., Spitzer, R. L., Gibbon, M., \& Williams, J. B. W. (2001). Structured Clinical Interview for DSM-IV-TR Axis I Disorders, research version, non-patient edition. (SCID-I/NP). New York: Biometrics Research, New York State Psychiatric Institute.

Foster, G. D., Wadden, T. A., Swain, R. M., Stunkard, A. J., Platte, P., \& Vogt, R. A. (1998). The eating inventory in obese women: Clinical correlates and relationship to weight loss. International Journal of Obesity and Related Metabolic Disorders, 22, 778-785.

Hainer, V., Kunesova, M., Bellisle, F., Parizkova, J., Braunerova, R., Wagenknecht, M., et al. (2006). The eating inventory, body adiposity and prevalence of disease in a quota sample of Czech adults. International Journal of Obesity (London), 30, 830-836.

Hamilton, M. (1960). A rating scale for depression. Journal of Neurology, Neurosurgery, and Psychiatry, 23, 62.

Hays, N. P., Bathalon, G. P., McCrory, M. A., Roubenoff, R., Lipman, R., \& Roberts, S. B. (2002). Eating behavior correlates of adult weight gain and obesity in healthy women aged 55-65 y. American Journal of Clinical Nutrition, 75, 476-483.

Jones, S. H., Thornicroft, G., Coffey, M., \& Dunn, G. (1995). A brief mental health outcome scale-reliability and validity of the Global Assessment of Functioning (GAF). The British Journal of Psychiatry, 166, 654-659.

Knolle-Veentjer, S., Huth, V., Ferstl, R., Aldenhoff, J. B., \& Hinze-Selch, D. (2008). Delay of gratification and executive performance in individuals with schizophrenia: $\mathrm{Pu}-$ tative role for eating behavior and body weight regulation. Journal of Psychiatric Research, 42, 98-105.

Lauzon-Guillain, B., Basdevant, A., Romon, M., Karlsson, J., Borys, J. M., \& Charles, M. A. (2006). Is restraint eating a risk factor for weight gain in a general population? American Journal of Clinical Nutrition, 83, 132-138.

Lawson, O. J., Williamson, D. A., Champagne, C. M., DeLany, J. P., Brooks, E. R., Howat, P. M., et al. (1995). The association of body weight, dietary intake, and energy expenditure with dietary restraint and disinhibition. Obesity Research, 3, 153-161.
Lindroos, A. K., Lissner, L., Mathiassen, M. E., Karlsson, J., Sullivan, M., Bengtsson, C. et al. (1997). Dietary intake in relation to restrained eating, disinhibition, and hunger in obese and nonobese Swedish women. Obesity Research, 5, 175-185.

Lowe, M. R., Annunziato, R. A., Markowitz, J. T., Didie, E., Bellace, D. L., Riddell, L., et al. (2006). Multiple types of dieting prospectively predict weight gain during the freshman year of college. Appetite, 47, 83-90.

McEwen, B. S., \& Stellar, E. (1993). Stress and the individual. Mechanisms leading to disease. Archives of Internal Medicine, 153, 2093-2101.

Miller, D. B., \& O'Callaghan, J. P. (2002). Neuroendocrine aspects of the response to stress. Metabolism, 51, 5-10.

Parsons, B., Allison, D. B., Loebel, A., Williams, K., Giller, E., \& Romano, S. (2009). Weight ef fects associated with antipsychotics: A comprehensive database analysis. Schizophrenia Research, 110, 103-110.

Savage, J. S., Hoffman, L., \& Birch, L. I. (2009). Dieting, restraint, and disinhibition predict women's weight change over 6 y. American Journal of Clinical Nutrition, 90, 33-40.

Sentissi, O., Viala, A., Bourdel, M. C., Kaminiski, F., Bellisle, F., Olié, J. P., et al. (2009). Impact of antipsychotic treatments on the motivation to eat: Preliminary results in 153 schizophrenic patients. International Clinical Psychopharmacology, 24, 257-264.

Stata Corporation (2002). Stata statistics/data analysis. (7.0). College Station, TX: Stata Corporation.

Stunkard, A. J., \& Messick, S. (1985). The three-factor eating questionnaire to measure dietary restraint, disinhibition and hunger. Journal of Psychosomatic Research, 29, 71-83.

Stunkard, A. J., \& Messick, S. (1988). Eating inventory manual. San Antonio, TX: The Psychological Corporation.

Vanina, Y., Podolskaya, A., Sedky, K., Shabab, H., Siddiqui, A., Munshi, F., et al. (2002) Body weight changes associated with psychopharmacology. Psychiatric Services, $53,842-847$.

Williamson, D. A., Lawson, O. J., Brooks, E. R., Wozniak, P. J., Ryan, D. H., Bray, G. A., et al. (1995). Association of body mass with dietary restraint and disinhibition. Appetite, $25,31-41$.

Young, R. C., Biggs, J. T., Zieler, V. E., \& Meyer, D. A. (1978). A rating scale for mania: Reliability, validity and sensitivity. The British Journal of Psychiatry, 133, 429-435. 